\title{
Primary Sjögren's Syndrome Complicated by Sarcoidosis
}

\author{
Masayuki Mryata, Yuuko Takase, Hiroko Kobayashi, Masaki Kokubun, Akiko Yoshimura*, \\ Yutaka KatsuUrA**, Tomoe NishimaKi and Reiji KasuKawa
}

\begin{abstract}
Sjögren's syndrome and sarcoidosis share several common features, such as keratoconjunctivitis sicca, swelling of parotid glands, lung involvement, cutaneous anergy, $\mathbf{T}$ cell-mediated immunodeficiency, an increased $\mathrm{CD4}^{+} / \mathrm{CD8}^{+}$lymphocyte ratio, and association with the human leucocyte antigen (HLA)-B 8 and DR 3 haplotypes. However, only five patients with primary Sjögren's syndrome and sarcoidosis have been previously reported in the English language literature. The rare case of a 49-year-old Japanese woman with primary Sjögren's syndrome complicated by sarcoidosis is described. The serum angiotensin-converting enzyme level was increased, and histological examination of lung and skin biopsies revealed noncaseating granulomas, indicating that her primary Sjögren's syndrome was complicated by sarcoidosis.
\end{abstract}

(Internal Medicine 37: 174-178, 1998)

Key words: human leucocyte antigen (HLA), dry eye, dry mouth

\section{Introduction}

Both Sjögren's syndrome and sarcoidosis are diseases of unknown etiology. Sjögren's syndrome is characterized by symptoms of dry eyes and a dry mouth, and is sometimes accompanied by bilateral enlargement of the salivary and lacrimal glands. Subclinical involvement of the parotid glands and lacrimal glands is relatively common in sarcoidosis patients, although the swelling of these glands is not frequently evident. However, individuals with sarcoidosis can exhibit clinical features similar to those of Sjögren's syndrome (1). Here, we now describe a patient with well-documented primary Sjögren's syndrome complicated by sarcoidosis.

As far as we are aware, only five cases of primary Sjögren's syndrome with sarcoidosis have been described in the English language literature. We discuss the common and discriminating features of Sjögren's syndrome and sarcoidosis.

For editorial comment, see also $\mathrm{p} 110$.

\section{Case Report}

A 49-year-old Japanese woman, with a history of pulmonary tuberculosis from the age of 15 , complained of having a dry mouth in July 1990 and was referred to the Department of
Otolaryngology in Saiseikai Fukushima Hospital. No collectable saliva was produced during a 15 -min period without stimulation. Histological analysis of a minor salivary gland in an oral mucosa biopsy revealed focal lymphocytic sialadenitis with degeneration of the ductular epithelium (Fig. 1). A Schirmer test resulted in $3 \mathrm{~mm}$ wetting in 5 minutes. Blood tests revealed anemia (red blood cell (RBC), $413 \times 10^{4} / \mathrm{cmm}$; hemoglobin $(\mathrm{Hb}), 9.6 \mathrm{~g} / \mathrm{dl})$, leukocytopenia $(3,000 / \mathrm{cmm})$ and polyclonal hypergamma globulinemia: immunoglobulin $\mathrm{G}(\mathrm{IgG}), 3,206$ $\mathrm{mg} / \mathrm{dl}$ (normal, 800 to $1,950 \mathrm{mg} / \mathrm{dl}$ ); immunoglobulin A (IgA), $480 \mathrm{mg} / \mathrm{dl}$ (normal, 80 to $410 \mathrm{mg} / \mathrm{dl}$ ) and immunoglobulin M $(\operatorname{IgM}), 510 \mathrm{mg} / \mathrm{dl}$ (normal, 68 to $290 \mathrm{mg} / \mathrm{dl})$. The rheumatoid factor was $2+$ and complement $\left(\mathrm{CH}_{50}\right)$ was $34 \mathrm{U}$ (normal, 30 $40 \mathrm{U}$ ). The titer of the antinuclear antibody was 1:2,560 (homogeneous and nucleolar pattern), but LE test was negative. The titers of antibodies to SS-A and SS-B antigens were higher than 1:256 and 1:8, respectively, in a double immunodiffusion test. The patient was referred to the Department of Internal Medicine in the same hospital in order to eliminate the possibility of other collagen diseases. She did not exhibit any symptoms such as fever, erythema, skin sclerosis, Raynoud's phenomenon, myalgia or arthritis when she was referred to an internist. On the basis of these observations, primary Sjögren's syndrome was diagnosed, and treatment with prednisolone $(10 \mathrm{mg} / \mathrm{day})$ was started.

She suddenly stopped taking prednisolone without permis-

From the Department of Internal Medicine II, Fukushima Medical College, *the Department of Gastroenterology and **the Department of Internal Medicine, Saiseikai Fukushima Hospital, Fukushima

Received for publication June 18, 1997; Accepted for publication October 15, 1997

Reprint requests should be addressed to Dr. Masayuki Miyata, the Department of Internal Medicine II, Fukushima Medical College, 1 Hikarigaoka, Fukushima 960-1295 
sion from her doctor in April 1996, and subsequently developed polyarthralgia and papulae on both knees and elbows (Fig. 2). Thereafter, she complained of a dry cough. A chest X-ray revealed fine nodular shadows in the whole lung (Fig. 3A), and computed tomography of the whole lung revealed fine nodular lesions distributed around the alveoli and along the small

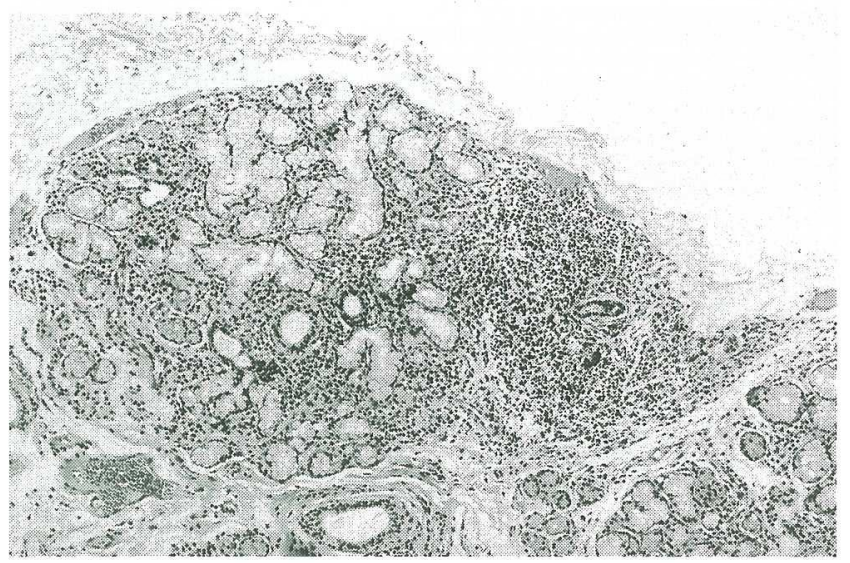

Figure 1. Histological examination of a minor salivary gland in the oral mucosa. Focal lymphocytic sialadenitis with degeneration of the ductular epithelium which is compatible with the histology of Sjögren's syndrome (HE stain, $\times 100)$.

A

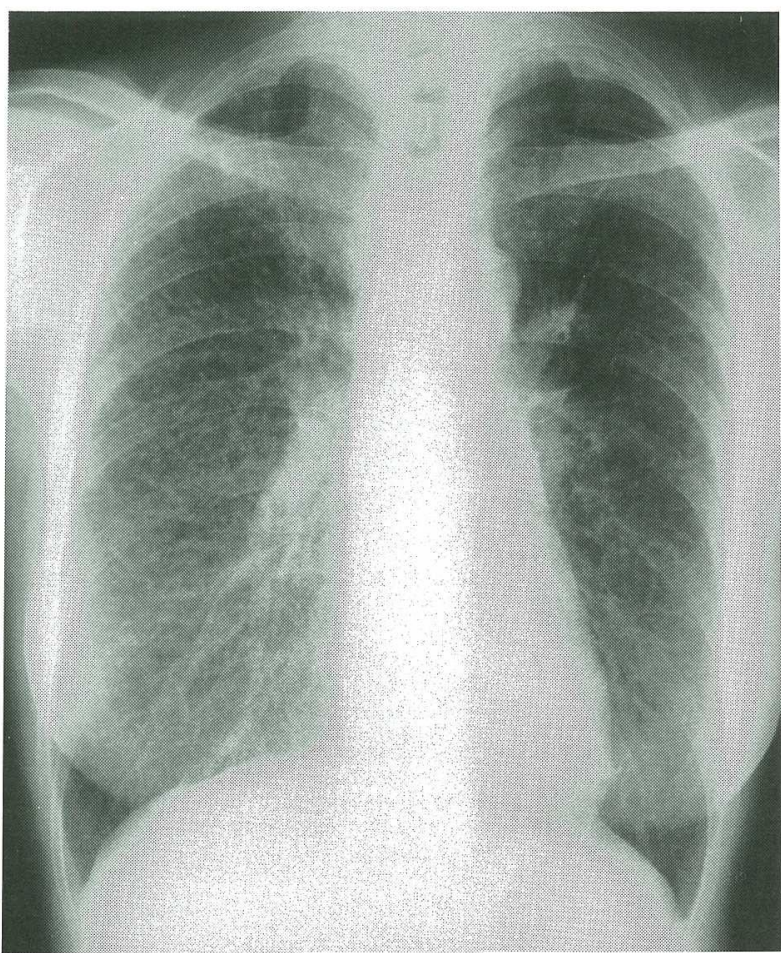

vessels and bronchioles (Fig. 3B). Swelling of the subaortic lymph nodes (\#5) was also evident (Fig. 3C).

The patient was referred to our department at Fukushima Medical College for further analysis of her lung lesion. A transbronchial lung biopsy and bronchoalveolar lavage performed in June 1996 revealed noncaseating granulomas not

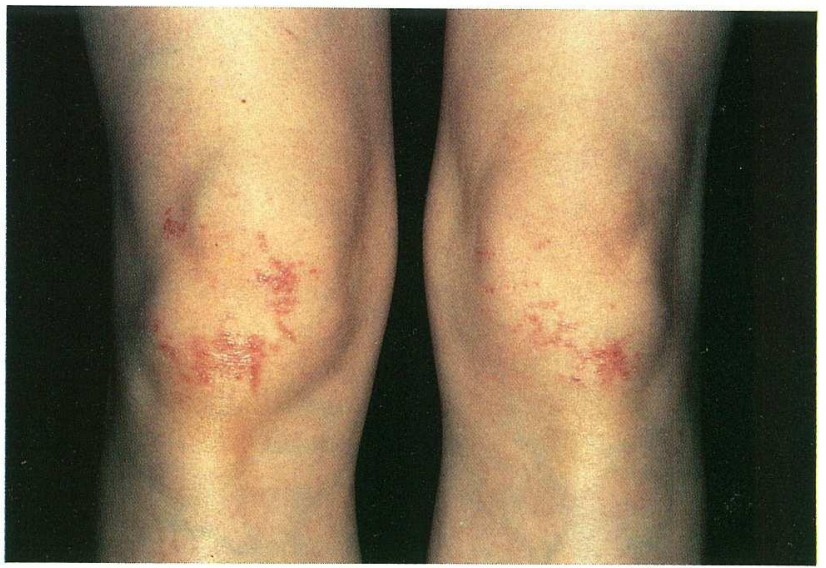

Figure 2. Linearly arranged, infiltrating, dark-red papulae around the patellar region.
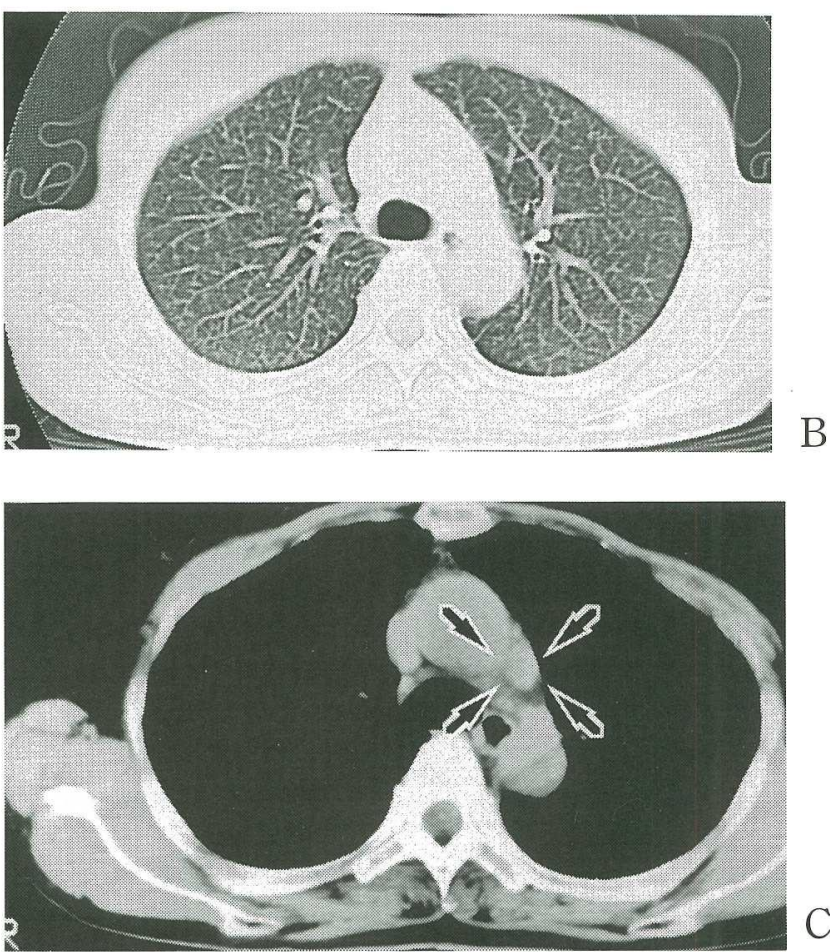

Figure 3. (A) Fine nodular lesions visible in the whole lung of the chest $X$-ray. (B and C) Chest computed tomography. Fine nodular shadows around the alveoli and along vessels and bronchioles ( $A$ and $B$ ) as well as swelling of the subaortic lymph nodes (\#5) as indicated by arrows (C) are evident. 


\section{Miyata et al}

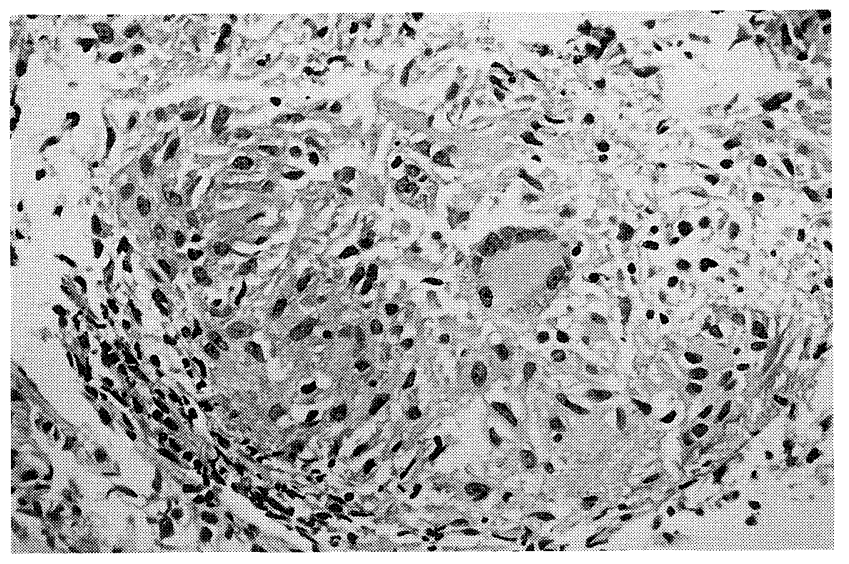

Figure 4. Histology of a transbronchial lung biopsy specimen. Noncaseating granulomas with many epitheliojd cells and a few Langhans-like giant cells, without any necrotic lesions, are evident. The granuloma lesion shown is partially surrounded by a moderate number of monocytes and lymphocytes (HE stain, $\times 200$ ).

exhibiting necrosis in the alveolar region (Fig. 4) and an increased ratio of $\mathrm{CD} 4^{+} / \mathrm{CD}^{+}$lymphocytes at 4.21 in the lavage fluid. Histological examination of a biopsy of her skin lesions on the knees also revealed noncaseating granulomas (Fig. 5). Both cultures and polymerase chain reaction analysis of sputum and bronchoalveolar lavage fluid were negative for Mycobacterium tuberculosis. The level of angiotensin-converting enzyme in serum was $32.7 \mathrm{U} / l$ (normal, 7 to $25 \mathrm{U} / l$ ).

Based on these findings, sarcoidosis was diagnosed $(2,3)$. The administration of salazosulfapyridine resolved the polyarthralgia as well as the skin lesions and cough. The fine nodular shadows disappeared as revealed by a chest X-ray and the size of the swollen hilar lymph nodes as revealed by chest computed tomography was also decreased (not shown).

\section{Discussion}

We described a Japanese woman with primary Sjögren's syndrome complicated by sarcoidosis. The arthralgia and papulae related to sarcoidosis appeared soon after she voluntarily stopped taking prednisolone, suggesting that her susceptibility to sarcoidosis had been suppressed by this drug. Her doctor prescribed prednisolone to prevent the development of hyperviscosity syndrome due to her hypergammaglobulinemia, and the treatment decreased these values from IgG, 3,206 mg/ dl, IgA, $480 \mathrm{mg} / \mathrm{dl}$ and IgM, $510 \mathrm{mg} / \mathrm{dl}$ on July 1990 to IgG, 2,283 mg/dl, IgA, $419 \mathrm{mg} / \mathrm{dl}$ and IgM, $228 \mathrm{mg} / \mathrm{dl}$ on May 13, 1996.

Serological typing studies have revealed associations between the HLA-DR 52 allele (4), the DR 52-associated antigens [DR 3, DR 5 (5) and -DR 6] and DR-8 (6) and sarcoidosis in Japanese patients. Among these sarcoidosispredisposing HLA-DR alleles, the present patient exhibited HLA-DR 6 and -DR 8. Although HLA-B 8 (7-9) and HLA-DR $3(10-12)$ are often associated with Sjögren's syn-

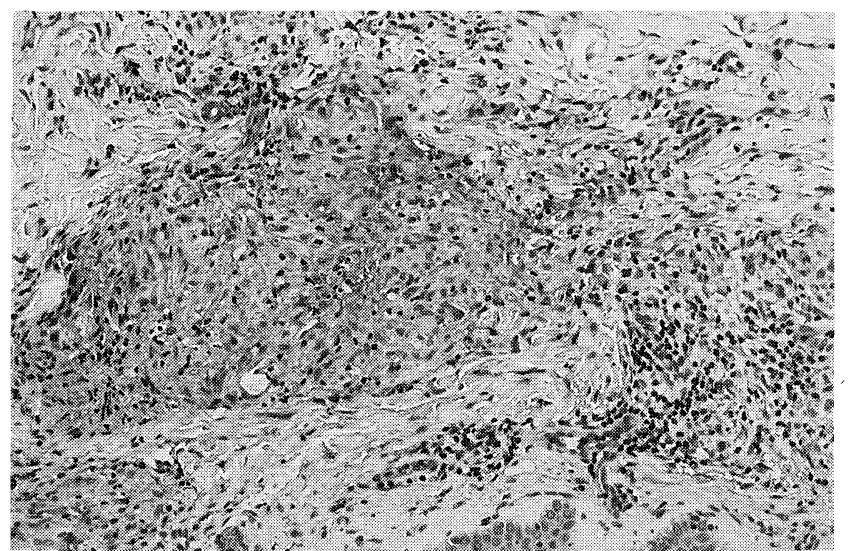

Figure 5. Histology of a papulae biopsy from the knee region. An irregularly shaped epithelioid cell granuloma is evident in the dermis. A few Langhans-like giant cells are evident in the granuloma, without any necrotic lesions. The granuloma is partially intermingled with a moderate number of monocytes and lymphocytes (HE stain, $\times 300$ ).

drome and sarcoidosis, our patient exhibited neither of these alleles.

The reported prevalence of abnormal pulmonary lesions varies widely; $9 \%$ occurrence in primary and secondary Sjögren's syndrome (13), a 37.5\% occurrence of diffuse interstitial lung disease in primary Sjögren's syndrome and an $11.8 \%$ occurrence in secondary Sjögren's syndrome (14) and an 8\% occurrence of lung fibrosis in primary Sjögren's syndrome (15), although the lesions are usually subclinical and rarely progressive. An abundance of mucosal glands renders the lung a primary target organ in this syndrome, resulting in conditions which include lymphoid interstitial pneumonia, lymphocytic alveolitis, xerotrachea, fibrosis, pseudolymphoma and malignant lymphoma (13). The first two of these pulmonary conditions were considered as candidates for diagnosis of the present case's lung lesions. Lymphoid interstitial pneumonia is classified as interstitial pneumonitis, with reticular shadows localized at the base of the lung in chest X-ray (16), and exhibits a clinical course that is basically chronic. Thus, this patient was not diagnosed with this condition. Alveolitis is a common lung lesion in both Sjögren's syndrome and sarcoidosis, necessitating histological analysis of the lung for its detection.

Almost all sarcoidosis patients exhibit swelling of the mediastinal and hilar lymph nodes as determined by computed tomography (17), as was evident in our patient. Approximately $90 \%$ of patients with sarcoidosis have granulomas in the lung or intrathoracic lymphoid tissue, or both (18). Granuloma formation along the alveolar septum and small vessels is a characteristic feature of lung lesions in sarcoidosis, resulting in fine nodular shadows in the lung field on both chest X-ray and computed tomography examination.

Tuberculosis has been proposed as one of the pathogenic factors for sarcoidosis and $4 \%$ of sarcoidosis have had tuberculosis (19). The present patient had a history of lung tuberculosis 
Primary Sjögren's Syndrome with Sarcoidosis

Table 1. Clinical Features and Laboratory Data of Patients with both Primary Sjögren's Syndrome and Sarcoidosis

\begin{tabular}{|c|c|c|c|c|c|}
\hline Patient/Reference & Patient $1 /(23)$ & Patient $2 /(28)$ & Patient 3/(29) & Patient $4 /(30)$ & Patient $5 /(31)$ \\
\hline Age (years)/gender & $34 / \mathrm{F}$ & $57 / \mathrm{F}$ & $42 / \mathrm{M}$ & $60 / \mathrm{F}$ & $45 / \mathrm{M}$ \\
\hline Duration of preceding disease (years) & 6 & 10 & 1 & 25 & 1 \\
\hline Symptoms & None & $\begin{array}{l}\text { Dry eyes and mouth, } \\
\text { dry cough exertional dyspnea }\end{array}$ & $\begin{array}{l}\text { Obstructive jaundice } \\
\text { NR }\end{array}$ & $\begin{array}{l}\text { Swelling of parotid glands, generalized arthralgia, } \\
\text { dry eyes, mouth, and vagina }\end{array}$ & $\begin{array}{l}\text { Dry mouth, dysphagia, } \\
\text { tiredess, Raynaud's phenomenon }\end{array}$ \\
\hline Rheumatoid factor & Negative & $1: 256$ & NR & $1: 40$ & $(++)$ \\
\hline Antinuclear antibodies & NR & $1: 400$ & NR & $1: 320$ & $(++)$ \\
\hline Antibodies to SS-A antigen & NR & $(+)$ & NR & NR & Negative \\
\hline Antibodies to SS-B antigen & NR & $(+)$ & NR & NR & Negative \\
\hline Chest X-ray & Normal & Normal & NR & Bilateral hilar lymph node enlargement & Bilateral hilar lymph node enlargement \\
\hline Angiotensin converting enzyme & NR & NR & NR & Normal & $(+)$ \\
\hline Histology of biopsied tissue & $\begin{array}{l}\text { Lung - sarcoidosis } \\
\text { Salivary gland - SS }\end{array}$ & $\begin{array}{l}\text { Lung - sarcoidosis } \\
\text { Salivary gland - SS }\end{array}$ & NR & $\begin{array}{l}\text { Lung - sarcoidosis } \\
\text { Salivary gland - SS }\end{array}$ & $\begin{array}{l}\text { Lung - sarcoidosis } \\
\text { Salivary gland - SS }\end{array}$ \\
\hline Pattern of onset & SS preceded sarcoidosis & SS preceded sarcoidosis & SS preceded sarcoidosis & SS preceded sarcoidosis & Sarcoidosis preceded SS \\
\hline
\end{tabular}

NR: not recorded, SS: Sjögren's syndrome.

at the age of 15 . Therefore, the occurrence of miliary tuberculosis in the lung field should also be considered in the differential diagnosis of her lung lesions. The erythrocyte sedimentation rate was $68 \mathrm{~mm} / \mathrm{h}$, but the CRP value was less than $0.1 \mathrm{mg} /$ $\mathrm{ml}$. Sputum and bronchoalveolar lavage fluid were negative for Mycobacterium tuberculosis. The level of angiotensin-converting enzyme in serum and the $\mathrm{CD} 4^{+} / \mathrm{CD}^{+}$lymphocyte ratio in bronchoalveolar lavage fluid were also high, both of which indicate that the patient no longer had tuberculosis.

Sjögren's syndrome and sarcoidosis share several immunological features, including cutaneous anergy, $\mathrm{T}$ cell-mediated immunodeficiency and B cell activation resulting in polyclonal hypergamma globulinemia. Accordingly, various clinical features are common to both Sjögren's syndrome and sarcoidosis. Clinically manifest parotid involvement occurs in 4 to $6 \%$ of sarcoidosis patients $(20,21)$, whereas subclinical involvement of minor salivary glands is apparent in about $50 \%$ of such patients (22). The frequency of eye involvement in sarcoidosis varies from $10 \%$ (23) to $70 \%$ (20), depending on the diagnostic criteria used.

Infectious agents, allergy, autoimmunity, genetic factors, and endocrine factors have been speculated to be involved in the development of Sjögren's syndrome. Interest in the relationship between viruses and Sjögren's syndrome began because some Sjögren's syndrome patients develop lymphoid malignancies (24). Viruses most likely to induce Sjögren's syndrome are either sialotropic or lymphotropic. Such viruses include the Epstein-Barr virus (25), HHV-6 (26) and retroviruses (27).

Infectious agents, chemicals and drugs, allergy, autoimmunity, and genetic factors have all been explored as possible causes of sarcoidosis. It has been postulated that $\mathrm{T}$ cell defects may be a result of virus infection.

Even though Sjögren's syndrome and sarcoidosis share immunological and genetic characteristics, we are aware of only five individuals with both primary Sjögren's syndrome and sarcoidosis who have been described in the English language literature $(23,28-31)$ (Table 1$)$. However, the number of such patients may be underestimated, because clinical symptoms of both diseases are frequently subclinical. The possibility of the simultaneous occurrence of these two conditions should therefore be considered in patients with a dry mouth and dry eyes. The possibility of misdiagnosing individuals who present with bilateral enlargement of the parotid and lacrimal glands, xerostomia, and keratoconjunctivitis sicca as having Sjögren's syndrome rather than sarcoidosis should also be kept in mind (1). Histological examination of a mucosal minor salivary gland specimen from this patient revealed acinar atrophy, mild fibrosis, and marked periductal focal lymphocyte infiltration. These observations were subsequently interpreted as indicating the early involvement of labial salivary glands in sarcoidosis (1).

Due to the many common features with respect to etiology, genetics, immunology and clinical findings between Sjögren's syndrome and sarcoidosis, a diagnosis of Sjögren's syndrome or sarcoidosis should be based on several criteria, including the presence of antinuclear antibodies, such as antibodies to SS-A and SS-B antigens, a change in angiotensin-converting enzyme levels, and clinical and histological observations.

Acknowledgements: We thank Drs. O. Suzuki in the Department of Pathology I and K. Iwatsuki and Y. Nihei in the Department of Dermatology of Fukushima Medical College for histological preparation of the lung and skin specimens, respectively.

This work was supported in part by a grant from the Foundation of Rheumatism Research Committee, Ministry of Health and Welfare of Japan.

\section{References}

1) Melson RD, Speight PM, Ryan J, Perry JD. Sarcoidosis in a patient 


\section{MiYata et al}

presenting with clinical and histological features of primary Sjögren's syndrome. Ann Rheum Dis 47: 166, 1988.

2) Hunninghake GW, Crystal RG. Pulmonary sarcoidosis: a disorder mediated by excess helper T-lymphocyte activity at sites of disease activity. $\mathrm{N}$ Engl J Med 305: 429, 1981.

3) Studdy P, Bird R, James DG. Serum angiotensin-converting enzyme (SACE) in sarcoidosis and other granulomatous disorders. Lancet ii: 1331, 1978.

4) Kunikane H, Abe S, Tsuneta Y, et al. Role of HLA-DR antigens in Japanese patients with sarcoidosis. Am Rev Respir Dis 135: 688, 1987.

5) Abe S, Yamaguchi E, Makimura S, Okazaki N, Kunikane H, Kawakami Y. Association of HLA-DR with sarcoidosis: correlation with clinical course. Chest 92: 488, 1987.

6) Ina $Y$, Takeda K, Yamamoto M, Morishita M, Senda Y, Torii Y. HLA and sarcoidosis in the Japanese. Chest 95: 1257, 1989.

7) Brewerton DA, Cockburn C, James DC, James DG, Neville E. HLA antigens in sarcoidosis. Clin Exp Immunol 27: 227, 1977.

8) Guyatt GH, Bensen WG, Stolmon LP, Fagnilli L, Singal DP. HLA-B8 and erythema nodosum. Can Med Assoc J 127: 1005, 1982.

9) Hedfors E, Lindstrom F. HLA-B8/DR3 in sarcoidosis. Correlation to acute onset disease with arthritis. Tissue Antigens 22: 200, 1983.

10) Chused TM, Kassan SS, Opelz G, Moutsopoulos HM, Terasaki PI. Sjögren's syndrome associated with HLA-Dw3. N Engl J Med 296: 895, 1977.

11) Wilson RW, Provost TT, Bias WB, et al. Sjögren's syndrome: influence of multiple HLA-D region alloantigens on clinical and serologic expression. Arthritis Rheum 27: 1245, 1984.

12) Gardner J, Kennedy HG, Hamblin A, Jones E. HLA associations in sarcoidosis: a study of two ethnic groups. Thorax 39: 19, 1984.

13) Strimlan CV, Rosenow EC, Divertie MB, Harrison EG Jr. Pulmonary manifestations of Sjögren's syndrome. Chest 70: 354, 1976.

14) Papathanasiou MP, Constantopoulos SH, Tsampoulas C, Drosos AA, Moutsopoulos HM. Reappraisal of respiratory abnormalities in primary and secondary Sjögren's syndrome-A controlled study. Chest 90: 370, 1986.

15) Gardiner P, Ward C, Allison A, et al. Pleuropulmonary abnormalities in primary Sjögren's syndrome. J Rheumatol 20: 831, 1993.

16) Colby TV, Carrington CB. Lymphoreticular tumors and infiltrates of the lung. Pathol Annu 18 Pt 1: 27, 1983.

17) Nishimura $\mathrm{K}$, Itoh $\mathrm{H}$. Radiologic findings of pulmonary sarcoidosis in
Japan. Saishin Igaku 43: 1474, 1988 (Abstract in English).

18) James DG, Neville E, Siltzbach LE. A worldwide review of sarcoidosis. Ann NY Acad Sci 278: 321, 1976.

19) Schumacher HR Jr. Sarcoidosis. in: Arthritis and Allied Conditions, Koopman WJ, Ed. Williams \& Wilkins/A Waverly Company, Pennsylvania, 1996, p. 1689.

20) Crick RP, Hoyle C, Smellie H. The eyes in sarcoidosis. Br J Ophthalmol 45: 461, 1961

21) Turiaf J, Battesti JP. Sarcoidosis according to the study of 350 cases observed for 15 years in a pneumology department. Rev Tuberc Pneumol (Paris) 35: 569, 1971.

22) Turiaf J, Battesti JP, Mark A, Basset F. Données de la biopsie labiale des glands salivaries accessoires pour le diagnostic histopathologique de la sarcoidose. Rev Franç Tuberc Mal Resp 3: 271, 1975 (in French).

23) Turiaf J, Battesti JP. Gougerot-Sjögren syndrome and sarcoidosis. Ann NY Acad Sci 278: 401, 1976.

24) FlescherE, Talal N. Do viruses contribute to the development of Sjögren's syndrome? Am J Med 90: 283, 1991 (editorial comment).

25) Tateishi M, Saito I, Yamamoto K, Miyasaka N. Spontaneous production of Epstein-Barr virus by B lymphoblastoid cell lines obtained from patients with Sjögren's syndrome. Possible involvement of a novel strain of Epstein-Barr virus in disease pathogenesis. Arthritis Rheum 36: 827, 1993.

26) Fox RI, Luppi M, Kang HI, Ablashi D, Josephs S. Detection of high levels of human herpes virus-6 DNA in a lymphoma of a patient with Sjögren's syndrome (letter). J Rheumatol 20: 764, 1993.

27) Mariette $X$, Cherot P, Cazals D, Brocheriou C, Brouet JC, Agbalika F. Antibodies to HTLV-1 in Sjögren's syndrome (letter). Lancet 345: 71, 1995.

28) Deheinzelin D, de Carvalho CRR, Tomazini ME, Barbas Filho JV, Saldiva PHN. Association of Sjögren's syndrome and sarcoidosis. Report of a case. Sarcoidosis 5: 68, 1988.

29) Johnson CD. Obstructive jaundice in a patient with ulcerative colitis, Sjögren's syndrome and sarcoidosis. J R Soc Med 82: 362, 1989.

30) Justiniani FR. Sarcoidosis complicating primary Sjögren's syndrome. Mt Sinai J Med 56: 59, 1989.

31) Koopmans PP, Bodeutsch C, de Wilde PC, Boerbooms AM. Primary Sjögren's syndrome presenting as a case of sarcoidosis and a suspected pancreatic tumour. Ann Rheum Dis 49: 407, 1990. 